\title{
“A alma da fome é política!" Lutemos por sobrevivência, dignidade e mudança
}

Floriano Godinho de Oliveira, Leandro Dias de Oliveira, Regina Helena Tunes e D'Jeanine Candido

\section{(2) OpenEdition}

1 Journals

\section{Edição electrónica}

URL: https://journals.openedition.org/espacoeconomia/21452

DOI: 10.4000/espacoeconomia. 21452

ISSN: 2317-7837

\section{Editora}

Núcleo de Pesquisa Espaço \& Economia

\section{Refêrencia eletrónica}

Floriano Godinho de Oliveira, Leandro Dias de Oliveira, Regina Helena Tunes e D'Jeanine Candido, «"A alma da fome é política!" Lutemos por sobrevivência, dignidade e mudança», Espaço e Economia [Online], 22 | 2021, posto online no dia 14 janeiro 2022, consultado o 11 agosto 2022. URL: http:// journals.openedition.org/espacoeconomia/21452 ; DOI: https://doi.org/10.4000/espacoeconomia. 21452

Este documento foi criado de forma automática no dia 11 agosto 2022.

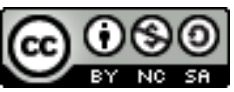

Creative Commons - Atribuição-NãoComercial-Compartilhalgual 4.0 Internacional - CC BY-NC-SA 4.0 https://creativecommons.org/licenses/by-nc-sa/4.0/ 


\title{
"A alma da fome é política!" Lutemos por sobrevivência, dignidade e mudança
}

\author{
Floriano Godinho de Oliveira, Leandro Dias de Oliveira, Regina \\ Helena Tunes e D'Jeanine Candido
}

1 Espaço e Economia: Revista Brasileira de Geografia Econômica chega a sua vigésima-segunda edição. Em sua capa, num registro em preto e branco, tem destaque a fotografia do trabalho de catadores de resíduos no antigo lixão da cidade de Feira de Santana, no estado da Bahia. Uma imagem incômoda e forte, mas necessária, com escopo numa categoria de trabalhadores que, segundo estimativa de 2010 do Instituto Brasileiro de Geografia e Estatística (IBGE), era composta por mais de 230 mil brasileiros, sendo aproximadamente 50 mil somente no estado do Rio de Janeiro. É uma coletividade bastante complexa, envolvendo desde catadores de rua até cooperativados, com trabalho organizado e exercendo uma importante função social, atuando para dignificar o trabalho realizado e instituir formas de negociação menos exploratórias e injustas (CRUZ, WANDERLEY, RIBEIRO, 2021). Os catadores de resíduos cumprem um papel simbólico: vivem da coleta de rejeitos para a própria sobrevivência e de sua família, gerados por uma sociedade profundamente segregada, na qual a abundância é seletiva e o descarte é a regra para que as engrenagens produtivas permaneçam funcionando em moto-contínuo.

O sociólogo Herbert de Souza, o Betinho, escreveu o artigo "A alma da fome é política!" que recuperamos no título - para o Jornal do Brasil há quase trinta anos. Dolorosamente, ele dizia que passamos a encarar com naturalidade o fato de termos nos consolidado como um país de miseráveis (SOUZA, 1993). "A fome é a realidade, o efeito e o sintoma", prossegue o sociólogo, e para se acabar com a fome é necessário mais que dar comida e gerar emprego, mas "reconstruir radicalmente toda a sociedade". Ao seu turno, na clássica obra Geografia da Fome (1984 [1946], p. 289), Josué de Castro apontava a dualidade da civilização brasileira, com a prosperidade industrial combinada com uma "estrutura agrária arcaica, de tipo semicolonial, com manifesta tendência à monocultura 
latifundiária, a principal responsável pela sobrevivência da fome no quadro social brasileiro". Para o autor, é essa forma arcaica de estrutura, de propriedade e de relações de trabalho no campo o fator preponderante para o problema da fome no país.

3 Apesar da fome, da miséria e da segregação terem profundas raízes históricas no país, causou recente comoção o relato publicado no Jornal Extra, do Rio de Janeiro, acerca da constante fila que se forma, na Zona Sul carioca, assim que um caminhão que recolhe ossos e pelancas de supermercados da cidade estaciona. 0 "caminhão de ossos" é mais um exemplo revoltante, num país cujos índices de desemprego atingiram 14,4 milhões de brasileiros no segundo trimestre de 2021 e a inflação ultrapassou $10 \%$ no ano de 2021, atingindo os dois dígitos pela primeira vez desde fevereiro de 2016 (SOUZA, SABÓIA, 2021). Antes transformado em ração de animais, cada pedaço de osso agora é incluído em sopas ou colocado no arroz, no feijão ou em qualquer outro preparo. Os depoimentos cortantes da matéria, proferidos com sinceridade punjante, rapidamente repercutiram na imprensa nacional e internacional. Tom Philips, em reportagem do jornal londrino The Guardian, destacou que as fotografias de indigentes brasileiros vasculhando uma pilha de carcaças de animais em busca de comida revelavam o quanto a fome afeta o o país mais populoso da América Latina (PHILIPS, 2021).

4 Conforme estudos realizados pelo grupo de pesquisa Alimento para Justiça: Poder, Política e Desigualdades Alimentares na Bioeconomia, com sede na Freie Universität Berlin, da Alemanha, 125,6 milhões de brasileiros sofreram, em algum grau, com insegurança alimentar durante a pandemia, o que equivale a quase $60 \%$ da população brasileira (STROPASOLAS, GIOVANAZ, 2021). 0 estudo, disponível na internet, é revelador da atual situação (GALINDO et. al., 2021). Quando confrontado com o problema, na costumaz conversa junto aos seus fiéis prosélitos em frente ao Palácio da Alvorada, o presidente da república, Jair Bolsonaro, parabenizou a atual Ministra da Agricultura e afirmou: " $O$ agronegócio vai muito bem". Um conselho para os que mais precisam? "Vá plantar, vá criar boi. Faz o que eles estão fazendo. Trabalhe de domingo a domingo, porque o dono da fazenda não tem CLT" (LIPPELT, 2021).

5 O editorial da edição anterior de Espaço e Economia: Revista Brasileira de Geografia Econômica lembrou que vivemos tempos indescritíveis, indizíveis, inexprimíveis, mas não inexplicáveis, impassíveis ou indolentes (RIBEIRO, 2021). O Brasil atual, para nosso desespero, combina a mais dura pandemia da história com a beligerância política e o obscurantismo médico-científico daqueles que deveriam construir políticas públicas capazes de ao menos atenuarem os graves problemas do presente. 2021 terminou como mais um ano sombrio e não é simples ter expectativas nesse cenário. Mas não desanimemos e tenhamos esperanças para 2022.

$6 \quad 0$ ano que se inicia pode nos lembrar o 22 do século passado, o ano que mais lembramos da década de 1920, devido à Semana de Arte Moderna, produzindo uma revolução na cultura brasileira; a fundação do Partido Comunista Brasileiro, que criou um protagonismo em toda a década de 20 , por meio de atuações como as vinculadas ao Movimento Tenentista e à Coluna Prestes, que muito influíram nas transformações ocorridas nas décadas seguintes.

7 Em 2022, várias manifestações anunciam uma imensa onda de indignação contra os golpistas e fascistas que hoje estão no poder, com manifestações de artistas, intelectuais, forças sociais e, sobretudo, trabalhadores, contra o negacionismo e desmonte do Estado no Brasil. No espectro político, se fortalece uma Frente Ampla dos Partidos de Esquerda e se enuncia a possível formação de uma Federação de Partidos. 
Nesse contexto, produz-se a possível construção de uma alternativa política com amplo apoio popular, que nos faz crer que, como no passado, podemos ter uma nova virada em direção à constituição de um Estado democrático e popular.

\section{BIBLIOGRAFIA}

CASTRO, Josué de. Geografia da fome: o dilema brasileiro: pão ou aço. Rio de Janeiro: Edições Antares, 1984 (1946).

CRUZ, Uilmer Rodrigues Xavier da ; WANDERLEY, Luiz Jardim de Moraes; RIBEIRO, Luis Henrique Leandro. Escalas do desenvolvimento desigual na rede de produção da reciclagem fluminense: breve incursão por teorias econômicas baseadas em relações de poder. Espaço e Economia: Revista Brasileira de Geografia Econômica, Ano 10, número 21, janeiro-junho de 2021. Disponível em: http://journals.openedition.org/espacoeconomia/19534. Acesso em: 10 de janeiro de 2022.

GALINDO, Eryka; TEIXEIRA, Marco Antônio; DE ARAÚJO, Melissa; MOTTA, Renata; PESSOA, Milene; MENDES, Larissa; RENNO, Lúcio. Effects of the Covid-19 pandemic on food consumption and food security in Brazil. Freie Universität Berlin (Alemanha), Lateinamerika-Institut / Ökonomie Lateinamerikas, 2021. Disponível em: https://refubium.fu-berlin.de/handle/ fub188/29813. Acesso em: de janeiro de 2021.

LIPPELT, Vanessa. Com aumento da fome, Bolsonaro diz que brasil garante segurança alimentar do catar. Congresso em foco, Portal UOL, 03 de novembro de 2021. Disponível em: https:// congressoemfoco.uol.com.br/temas/direitos-humanos/com-aumento-da-fome-bolsonaro-dizque-brasil-garante-seguranca-alimentar-do-catar/. Acesso em: d janeiro de 2021.

PHILLIPS, Tom. Outcry in Brazil over photos of people scavenging through animal carcasses. The Guardian, 3 de outubro de 2021. Disponível em: https://www.theguardian.com/world/2021/oct/ 03/outcry-in-brazil-over-photos-of-people-scavenging-through-animal-carcasses. Acesso em: 10 de janeiro de 2022.

RIBEIRO, Guilherme. Resistência e esperança: lições em tempos de guerra. Editorial. Espaço e Economia: Revista Brasileira de Geografia Econômica, Ano 10, número 21, janeiro-junho de 2021. Disponível em: http://journals.openedition.org/espacoeconomia/18900. Acesso em: 10 de janeiro de 2022.

SOUZA, Herbert de. A alma da fome é política! Jornal do Brasil. Suplemento "Fome". Rio de Janeiro, 12 de setembro de 1993.

SOUZA, Rafael Nascimento de; SABÓIA Gabriel. Garimpo contra a fome: sem comida, moradores do Rio recorrem a restos de ossos e carne rejeitados por supermercados. Jornal Extra, 29 de setembro de 2021. Disponível em: https://extra.globo.com/noticias/rio/garimpo-contra-fomesem-comida-moradores-do-rio-recorrem-restos-de-ossos-carne-rejeitados-porsupermercados-25216735.html. Acesso em: 10 de janeiro de 2022.

STROPASOLAS, Pedro; GIOVANAZ, Daniel. Brasil com fome: pandemia e desmonte do Estado agravam drama dos trabalhadores. Brasil de Fato, São Paulo (SP), 11 de agosto de 2021. Disponível em: https://www.brasildefato.com.br/2021/08/11/brasil-com-fome-pandemia-e-desmonte-doestado-agravam-drama-dos-trabalhadores. Acesso em: 10 de janeiro de 2022. 


\section{AUTORES}

\section{FLORIANO GODINHO DE OLIVEIRA}

Professor do Programa de Pós-Graduação em Políticas Públicas e Formação Humana (PPFH) da Universidade do Estado do Rio de Janeiro. E-mail: fgodinho@uerj.br.

\section{LEANDRO DIAS DE OLIVEIRA}

Professor Associado do Departamento de Geografia (DGG-IA) e dos quadros permanentes do Programa de Pós-Graduação em Geografia (PPGGEO) e do Programa de Pós-Graduação Interdisciplinar em Humanidades Digitais (PPGIHD) da Universidade Federal Rural do Rio de Janeiro. E-mail: ldiasufrrj@gmail.com.

\section{REGINA HELENA TUNES}

Doutora em Geografia Humana, professora do Programa de Pós-graduação em Geografia da Universidade do Estado do Rio de Janeiro (PPGEO-UERJ). E-mail: tunesregina@gmail.com.

\section{D'JEANINE CANDIDO}

Licenciada em Geografia pela Universidade do Estado do Rio de Janeiro (FFP/UERJ) e mestranda do Programa de Pós-Graduação em Políticas Públicas e Formação Humana (PPFH) da Universidade do Estado do Rio de Janeiro. Secretária-Executiva de Espaço e Economia: Revista Brasileira de Geografia Econômica. E-mail: djeaninecandido@gmail.com. 